\title{
CHAMBERLIN'S SOLUTION IN A SPATIAL MARKET
}

\author{
Bruce L. Benson and Robert M. Feinberg*
}

\section{Introduction}

A rather large body of recent literature has explored the implications of various conjectural variations in spatial pricing models. ${ }^{1}$ Very different conclusions have been reached as to which conjecture is appropriate for spatial modeling. The purpose of this paper is to add to this debate through application to a spatial model of two sets of arguments which stress that entrepreneurs learn. The first was made by Chamberlin (1933, pp. 46-51) in his spaceless duopoly solution. Chamberlin was dissatisfied with the previously proposed models (e.g. Cournot, Edgeworth) because they assumed that naive duopolists never learn. He offered a duopoly solution in which entrepreneurs recognize their mutual interdependence and realize that the best they can do is to split the market and price as monopolists. Ferguson observed that "Chamberlin's solution has much to recommend it. Most important, his entrepreneurs behave in a sophisticated way in that they understand reality and act accordingly" (1969, p. 313) (emphasis added).

A recently emerging development in theoretical oligopoly is the concept of "consistent conjectures equilibria" (CCE) (e.g. see Bresnahan (1981), Perry (1982), Kamien and Schwartz (1983), Boyer and Moreaux (1983) and Holt (1985). The CCE concept is also based on the assumption that entrepreneurs learn. Thus, a CCE arises when "nothing in the comparative statics of equilibrium will reveal those conjectures to be wrong" (Bresnahan 1981, p. 943). Since Chamberlin began with a similar premise in deriving his duopoly solution, one might expect that his equilibrium would be identical to a CCE. This situation is clearly not the case in a spaceless setting since the spaceless CCE will fall between the Bertrand (price equal marginal cost) and Cournot equilibria depending upon the slope of the demand and cost functions (Bresnahan 1981). Chamberlin's solution, on the other hand, provides for a tacitly collusive equilibrium. We will show, however, that for an important special case of spatial competition, the two do converge.

\footnotetext{
*Professor of Economics at Florida State University and Senior Research Economist, U.S. Intemational Trade Commission, respectively. The authors wish to thank Charles Holt, Jr. for his very helpful comments on an earlier draft of this paper.
}

Spatial Duopoly Models

The essential difference between spatial and spaceless duopoly models is that in a spatial model consumers are assumed to be geographically distributed and transportation costs for the product in question are significant. Assume that two firms produce physically identical products and are located at geographically separated sites (points A and B in Figure 1). ${ }^{2}$ Consumers are evenly and continuously distributed between the two firms, and they pay the price charged by a firm plus the cost of transporting the product. Consequently, consumers will buy from the supplier offering the lowest delivered price. Individual consumer demand is a function of the full or delivered price of the product. Let all consumers have identical gross demands for the product supplied, defined by

$$
\text { (1) } q=f(P+t u) \text {. }
$$

Individual demand for each buyer is represented by $q$, while $P$ denotes a firm's mill or gate price, $t$ is the transport rate per unit of distance (assumed constant), and $\mathrm{u}$ is units of distance from the nearest seller. Since $\mathbf{u}$ is a variable, the effective (or net) demand facing a firm differs from consumer to consumer. Further assume that buyers pay the transport charges themselves so that producers are unable to price discriminate. ${ }^{3}$ In other words, the following presentation is of an f.o.b. pricing model.

The aggregate demand for firm $A, Q_{A}$, is

$$
Q_{A}\left(P_{A}, U\right)=\sigma U f\left(P_{A}+t u\right) d u,
$$

while firm B's aggregate demand, $Q_{B}$, is

$$
\mathrm{Q}_{\mathrm{B}}\left(\mathrm{P}_{\mathrm{B}}, \mathrm{D}-\mathrm{U}\right)=\int_{0}^{\mathrm{D}-\mathrm{U}} \mathrm{f}\left(\mathrm{P}_{\mathrm{B}}+\mathrm{tu}\right) \mathrm{du} .
$$

The total distance between A and B is denoted as D and $U$ represents the distance over which firm A sells. Thus, D-U is the portion of the market controlled by B. Also assume each firm faces an identical cost function

(4) $\mathrm{C}=\mathrm{C}\left(\mathrm{Q}_{\mathrm{i}}\right), \mathrm{i}=\mathrm{A}, \mathrm{B}$.

Firm A's profit relationship is

$$
\pi_{A}=P_{A} Q_{A}\left(P_{A}, U\right)-C_{A}\left(Q_{A}\left(P_{A}, U\right)\right),
$$

and profit maximization requires 
(6)

$$
\frac{d \pi_{A}}{d P_{A}}=Q+P A P \frac{\partial Q}{\partial P_{A}}+P \frac{\partial Q}{\partial U} \frac{\partial U}{\partial P_{A}}-\frac{\partial C_{A}}{\partial Q_{A}}
$$

$\frac{\partial Q_{A}}{\partial P_{A}}-\frac{\partial C_{A}}{\partial Q_{A}} \frac{\partial Q_{A}}{\partial U} \quad \frac{\partial U}{\partial P_{A}}=0$.

Note that this spatial duopolists conjecture appears as $\frac{\partial U}{\partial P}$. Thus marginal cost is set equal to the firm's $\partial \mathrm{P}_{\mathbf{A}}$

conjectured marginal revenue

$$
P_{A}+\frac{Q}{\frac{\partial Q_{A}}{\partial P_{A}}+\frac{\partial Q_{A}}{\partial U} \frac{\partial U}{\partial P_{A}}}=\frac{\partial C}{\partial Q_{A}}
$$

and the firm's profit maximizing price, therefore, is characterized as

$$
P_{A}=\frac{\partial C}{\partial Q_{A}}+\frac{Q_{A}}{\frac{\partial Q_{A}}{\partial P_{A}}-\frac{\partial Q_{A}}{\partial U} \frac{\partial U}{\partial P_{A}}}
$$

As noted above, each firm's expectations about his rival's behavior is represented by a conjecture about U. However, since consumers will buy from the firm offering the lowest delivered price, the service area boundary between the two firms occurs where delivered prices are equal (Capozza and Van Order, 1978):

(9) $\quad P_{A}+t U=P_{B}+t(D-U)$.

Therefore,

$$
U=\frac{1}{2 t}\left(P_{B}-P A+t D\right) .
$$

and

(11) $\frac{\partial \mathrm{U}}{\partial \mathrm{P}_{\mathrm{A}}}=\frac{(1}{2 \mathrm{t}} \frac{\left.\partial \mathrm{P}_{\mathrm{B}_{-}} 1\right)}{\partial \mathrm{P}_{\mathrm{A}}}$.

So, while spatial models typically assume price conjectures are made, there is an immediate correspondence to a boundary conjecture, $\partial \mathrm{U} / \partial \mathrm{P}_{\mathrm{A}}$

Firm B's profit maximizing equation is similar

$$
P_{B}=\frac{\partial C_{B}}{\partial Q_{B}}+\frac{Q_{B}}{-\frac{Q_{B}}{\partial P_{B}}-\frac{\partial B}{\partial U} \frac{\partial U}{\partial P_{B}}}
$$

Simultaneous solution of Equations (8), (9) and (12) will yield equilibrium values of $P_{A}, P_{B}$ and $U$. $P_{A}$ and $\mathrm{P}_{\mathrm{B}}$ depend upon the conjectural variation, but Ohta (1980) has proven that, given identical behavior (that is, identical expectations of price reactions so $\left.\partial \mathrm{P}_{\mathrm{B}} \partial \mathrm{P}_{\mathrm{A}}=\partial \mathrm{P}_{\mathrm{A}} / \partial \mathrm{P}_{\mathrm{B}}\right)$, identical production cost functions, and identical gross individual demands, $\mathrm{P}_{\mathrm{A}}$ $=\mathrm{P}_{\mathrm{B}}$ and $\mathrm{U}=\mathrm{D} / 2$ as in Figure $\mathrm{I}$. Let us now consider the most widely used conjectural variations employed in the spatial literature.

Capozza and Van Order explained the $\partial \mathrm{U} / \partial \mathrm{P}_{\mathrm{A}}$ and $\partial \mathrm{P}_{\mathrm{B}} / \partial \mathrm{P}_{\mathrm{A}}$ values for three of the commonly used conjectures in spatial competition (1978). They examined:

1) Loschian competition--each entrepreneur believes his market boundary is fixed (therefore $\partial \mathrm{U} / \partial \mathrm{P}_{\mathrm{A}}=\partial \mathrm{U} / \partial \mathrm{P}_{\mathrm{B}}=0$ ) and prices as a monopolist within that market;

2) Hotelling-Smithies competition (HS)--each firm believes his rival's mill price will not be changed (so $\partial \mathrm{P}_{\mathrm{A}} \partial \mathrm{P}_{\mathrm{B}}=\partial \mathrm{P}_{\mathrm{B}} / \partial \mathrm{P}_{\mathrm{A}}=0$ ); 4

3) Greenhut-Ohta competition (GO)--each firm expects its delivered price to its service area boundary will remain fixed.

We also shall consider:

4) Cournot competition--each entrepreneur anticipates that his rival's quantity will be held constant.

Since Loschian behavior assumes $\partial \mathrm{U} / \partial \mathrm{P}_{\mathrm{A}}=0$, it follows from Equation (11) that $\partial \mathrm{P}_{\mathrm{B}} / \partial \mathrm{P}_{\mathrm{A}}=1$. That is, the Loschian assumption is of a unitary price conjectural variation. HS competition is equivalent to the Bertrand conjecture in that it assumes a zero price conjectural variation, so $\partial \mathrm{U} / \partial \mathrm{P}_{\mathrm{A}}=-1 / 2 \mathrm{t}$ from Equation (11). In order for price to remain constant at the service area boundary in an f.o.b. model the GO entrepreneur must anticipate an equal and opposite price reaction $\left(\partial \mathrm{P}_{\mathrm{B}} / \partial \mathrm{P}_{\mathrm{A}}=-1\right)^{.5}$ Thus, $\mathrm{GO}$ behavior implies a $\partial \mathrm{U} / \partial \mathrm{P}_{\mathrm{A}}=1 / \mathrm{t}$. Clearly then, Equation (7) indicates that all else equal (demand and cost conditions) the Loschian price exceeds the HS price, which in turn exceeds the GO price.

Capozza and Van Order did not derive th $\partial \mathrm{U} / \partial \mathrm{P}_{\mathrm{A}}$ or $\partial \mathrm{P}_{\mathrm{B}} / \partial \mathrm{P}_{\mathrm{A}}$ value for Cournot competition to A's: 
although such a derivation can be made if a specific demand function is assumed rather than the general one employed here. 6 However, it is clear that the Cournot price and boundary conjectures must fall between the Loschian and HS values. Under Cournot behavior firm A expects firm B's output to be held constant so from equation (3),

$$
\frac{\partial Q_{B}}{\partial P_{A}}=\frac{\partial Q_{B}}{\partial P_{B}} \frac{\partial P_{B}}{\partial P_{A}}+\frac{\partial Q_{B}}{\partial U} \frac{\partial U}{\partial P_{A}}=0 .
$$

Since B's output is expected to remain constant, A believes that the change in B's sales due to a shift in $\mathrm{U}$ must just be offset by the change in B's output resulting from his price response. For example, suppose firm $\mathrm{A}$ is considering lowering its price. This change would expand A's market (U) and, therefore, contract B's (D-U). As B's market shrinks, it loses sales. Thus, given Cournot expectations, firm A must expect firm $B$ to lower price to regain its lost sales. Clearly then, $\partial \mathrm{P}_{\mathrm{B}} / \partial \mathrm{P}_{\mathrm{A}}>0$ so the Cournot price conjecture exceeds the HS price conjecture. Furthermore, $\partial \mathrm{P}_{\mathrm{B}} / \partial \mathrm{P}_{\mathrm{A}}<1$ because if $A$ 's price change is matched so that the market boundary remains unchanged B would simply be lowering its price to all its existing customers and expanding its output. Cournot behavior must, as a consequence, involve a price conjecture such that $1>$ $\partial \mathrm{P}_{\mathrm{B}} / \partial \mathrm{P}_{\mathrm{A}}>0$ and a boundary conjecture where $0>$ $\partial \mathrm{U} / \partial \mathrm{P}_{\mathrm{A}}>-1 / 2 \mathrm{t}$.

Now let us consider the price adjustments which arise under the various conjectural variations discussed above. HS, GO, and Cournot entrepreneurs do not believe their service area boundary is fixed. Each of these types of entrepreneur perceives a demand which is more elastic than the Loschian curve because he anticipates being able to gain distant customers by lowering price. Consider HS competition. Given the monopoly price that exists before entry of a second firm takes place, each HS firm, will lower price, anticipating higher profits. However, simultaneous adjustments by both firms imply that the market boundary does not change when both firms behave as HS pricers, even though it is expected to. Similar results arise with Cournot and GO behavior except that the Cournot perceived demand is less elastic than the HS demand while the GO curve is more elastic. In each case, the service area boundary remains constant even though it is expected to change.

The above discussion already suggests the sense in which Loschian behavior is a sophisticated conjecture in a spatial duopoly. When the duopolists simultaneously adjust price, the service area boundary does not change. Thus, the expectations of HS, GO and Cournot entrepreneurs do not correspond to the equilibrium that actually occcurs. Only Loschian firms recognize reality and expect the service area boundary to be fixed. ${ }^{7}$ Let us formally define "sophisticated" behavior a la Chamberlin to include: 1) recognition of reality and 2) tacitly collusive profit maximization. It has been demonstrated above that the Loschian entrepreneurs' expectations are correct and that joint profit maximization occurs as a consequence having been shown by Ohta (1980). In other words, Loschian prices are identical to collusive prices (Capozza and Van Order 1978) and correspond to the tacitly collusive duopoly outcome envisioned by Chamberlin.

\section{Consistent vs. Sophisticated Conjectural Equilibria}

Now let us consider how a Chamberlinian sophisticated conjecture solution compares with the CCE concept. A CCE occurs when the slope of the reaction function equals the conjecture. However, as Bresnahan explained in his spaceless duopoly model, there is in general no unique CCE. The consistent conjecture depends upon the slopes of the demand and cost functions. Thus, the consistent conjecture concept is clearly not equivalent to Chamberlin's sophisticated behavior argument, despite the fact that both arguments begin with the assumption that entrepreneurs learn. Bresnahan (1981), Perry (1982) and others who have explored the CCE hypothesis conclude that entrepreneurs will adopt expectations consistent with their observations because they learn.

Chamberlin, in a sense, carried the logic one step further and concluded that oligopolists, once they have recognized their mutual interdependence, learn enough to realize that the best they can do is split the market and set tacitly collusive prices. Thus, Chamberlin's entrepreneurs take advantage of their knowledge while entrepreneurs adopting consistent expectations simply react to it. Therefore, even though modern writers on consistent conjectures and Chamberlin started with identical assumptions about duopolists' ability to learn, Chamberlin carried this assumption further than the CCE model does so that his equilibrium solution is very different than the CCE, at least in a spaceless setting. For instance, if spaceless duopolists produce identical products and have constant marginal cost, the CCE is the Bertrand $\mathrm{P}=\mathrm{MC}$ solution (Bresnahan 1981). So a CCE may yield a result equivalent to perfect competition while Chamberlin's solution is always equivalent to the 
monopoly outcome. Even when marginal costs are not constant, the highest possible spaceless CCE duopoly price is that provided by Cournot behavior (Bresnahan, 1981) so that Chamberlin's spaceless equilibrium would never be a CCE.

The CCE and Chamberlinian sophisticated behavior are relatively more compatible in a spatial setting. In fact, under some very restrictive assumptions the two concepts converge to yield identical outcomes. Assume that consumers are uniformly distributed over a unit interval (i.e. $\mathrm{D}=1$ ), and they have perfectly inelastic demand of one unit. However, they are conscious of price to the degree that they buy from the seller with the lowest delivered price. Some may question the realism of these assumptions, but they have played an important role in numerous spatial papers following the lead of Hotelling (1929). The perfectly inelastic demand assumption can be modified, as in Capozza and Van Order (1977a), to include a maximum price consumers are willing to pay after which demand drops to zero without changing the conclusions which follow.

Now let firm $A$ face a constant marginal cost of c. Since each consumer buys one unit $Q_{A}=U$ and $\mathrm{Q}_{\mathrm{B}}=1$ - $\mathrm{U}$, substituting for $\mathrm{U}$ from equation (10) it follows that

$$
\pi_{A}=\left(\frac{P_{B}-P_{A}+t}{2 t}\right)\left(P_{A}-c\right)
$$

and profit maximization dictates

$$
\frac{d \pi_{A}}{\partial P_{A}}=P_{B}+t+c-2 P_{A}+\left(P_{A}-c\right) \frac{\partial P_{B}}{\partial P_{A}}=0
$$

Equation (16) can be rearranged as a reaction function

$$
P=\frac{P_{B}+t+c-c \frac{\partial P_{B}}{\partial P_{A}}}{2-\frac{\partial P_{B}}{\partial P_{A}}}
$$

Assuming identical conjectures, $\partial \mathrm{P}_{\mathrm{B}} / \partial \mathrm{P}_{\mathrm{A}}=$ $\partial \mathrm{P}_{\mathrm{A}} / \partial \mathrm{P}_{\mathrm{B}}$, consistency requires the slope of this reaction function to equal the conjecture:

$$
\begin{aligned}
\frac{\partial \mathrm{P}_{\mathrm{A}}}{\partial \mathrm{P}_{\mathrm{B}}}= & \frac{1}{2 \frac{\partial \mathrm{P}_{\mathrm{A}}}{\partial \mathrm{P}_{\mathrm{B}}}} \rightarrow 2 \frac{\partial \mathrm{P}_{\mathrm{A}}}{\partial \mathrm{P}_{\mathrm{B}}}-\frac{\partial \mathrm{P}_{\mathrm{A}}}{\partial \mathrm{P}_{\mathrm{B}}}-1=0 \\
& \rightarrow \frac{\partial \mathrm{P}_{\mathrm{A}}}{\partial \mathrm{P}_{\mathrm{B}}}-\quad 1=\frac{\partial \mathrm{P}_{\mathrm{A}}}{\partial \mathrm{P}_{\mathrm{B}}}=1 .
\end{aligned}
$$

In this special case, it is clear that the Loschian conjecture is not merely "sophisticated," but it also yields a CCE. The resulting price, in this case, is equal to whatever maximum consumers will pay. ${ }^{8}$

Once demand is assumed to be elastic, Loschian behavior, while sophisticated in a Chamberlin sense, can no longer be proven to imply a CCE. ${ }^{9}$ Therefore, once we move away from the assumption of perfectly inelastic demand, the question becomes this--if spatial entrepreneurs learn, do they adopt consistent or sophisticated behavior? The answer can only be obtained through empirical investigation, of course, and little empirical work has been done in the area of spatial pricing. Capozza and Attaran (1976) claimed to generate evidence which allowed them to reject Loschian behavior, but the theoretical predictions they tested arise only under restricted demand and cost function assumptions (Benson 1980). Actually, Capozza and Attaran really could only reject Loschian behavior by firms with constant marginal costs facing consumers with linear demands. Changing either function in their theoretical model alters the predictions and eliminates the justification for rejecting Loschian behavior. Charles Holt (1985), on the other hand, recently performed an experimental test of a spaceless oligopoly model and rejected the consistent conjectures hypothesis. Holt's conclusion may not hold in a spatial setting, of course; ${ }^{10}$ and rejection of the consistent conjectures argument certainly does not imply acceptance of the sophisticated behavior concept. Entrepreneurs may never learn--implying that neither sophisticated nor consistent conjectures are necessarily always appropriate. In this regard, experimental spatial duopoly markets were recently examined in order to see which conjecture best predicts the equilibria which arise (Benson and Feinberg 1988). There was evidence of learning, and the Loschian equilibrium did arise in a number of markets. However, other equilibria (e.g. Hotelling-Smithies and one near the Cournot solution) were also observed and information conditions also appeared to affect behavior. 


\section{Conclusion}

The Loschian conjecture in spatial pricing models corresponds to Chamberlin's sophisticated duopoly solution. That is, Loschian entrepreneurs recognize their mutual interdependence and realize that the best they can do is tacitly collude and split monopoly level profits. We further demonstrate that in a spatial market the consistent conjecture and Chamberlinian sophisticated conjecture are identical when individual consumer demands are perfectly inelastic. This observation contrasts sharply with the literature on consistent conjectures as it has developed with spaceless oligopoly models. Once demand is assumed to have some negative slope, the two concepts diverge, however, with Loschian behavior remaining the sophisticated conjecture while the consistent conjecture may take on different values depending on demand and cost functions.

\section{FOOTNOTES}

${ }^{1}$ See for example, M.L. Greenhut, Ming-Jeng Hwant, and Hiroshi Ohta (1975), Dennis Capozza and Kazim Attaran (1976), Capozza and Robert Van Order (1977a, 1977b, 1978, 1980), Bruce Benson (1979, 1980), Benson and Robert Feinberg (1988), Neil Dorward (1981), and Ohta (1980, 1981).

${ }^{2}$ Clearly spatially dispersed consumers open up the possibility of competition in terms of both price and locational choice, as in Harold Hotelling (j1929) and Arthur Smithies (1941), for example. However, analysis is limited here to price competition and locations are assumed to be fixed, even though the question of what might be the appropriate locational conjecture is an interesting one.

${ }^{3}$ Price discrimination is possible (and profitable) in a spatial model if firms can charge a delivered price, even when consumers have identical demand functions (Greenhut and Ohta 1975b). This occurs because when transport costs are subtracted from demand the elasticity of the resulting net demand changes. For example, with a linear individual demand dunction, net demand becomes increasingly inelastic at any price as more and more transport costs are subtracted. Thus, we are avoiding this added complication and assuming firms are unable to price discriminate.

${ }^{4}$ This behavior has also been called spatial Cournot Oligopoly (Martin Beckman 1972), although it clearly is not equivalent to the Cournot conjecture where $\partial \mathrm{Q}_{\mathrm{A}} / \partial \mathrm{Q}_{\mathrm{B}}=\partial \mathrm{Q}_{\mathrm{B}} / \partial \mathrm{Q}_{\mathrm{A}}=0$.

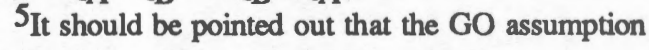
was developed in the context of a spatial price discrimination model where the $\partial \mathrm{P}_{\mathrm{B}} / \partial \mathrm{P}_{\mathrm{A}}=1$ implication does not necessarily hold (Greenhut and
Ohta 1975a). Rather, the assumption was intended to imply a horizontal delivered price schedule in the vincinity of the market boundary (a possibility in a discriminatory model but not under f.o.b. pricing). Thus, the originators of the assumption may not consider it appropirate to use the assumption in an f.o.b. model. However, we shall consider it since it is one of the most extreme of the price conjectures $\left(\partial \mathrm{P}_{\mathrm{B}} / \partial \mathrm{P}_{\mathrm{A}}=1\right)$ considered in spatial models--the other being the Loschian $\partial \mathrm{P}_{\mathrm{B}} / \partial \mathrm{P}_{\mathrm{A}}=1$.

${ }^{6} \mathrm{As}$ noted in equation (13) below, $\partial \mathrm{Q}_{\mathrm{B}} / \partial \mathrm{P}_{\mathrm{A}}=0$. Substitution of (11) into (13) provides

$$
\frac{\partial Q_{B}}{\partial P_{A}}=\frac{\partial Q_{B}}{\partial P_{B}} \frac{\partial P_{B}}{\partial P_{A}}+\frac{\partial Q_{B}}{\partial U} \frac{1}{2 t} \frac{\partial P_{B}}{\partial P_{A}}-1=0
$$

Therefore,

$$
\frac{\partial \mathrm{P}_{\mathrm{B}}}{\partial \mathrm{P}_{\mathrm{A}}}=+\frac{\frac{1}{2 t} \frac{\partial \mathrm{Q}_{\mathrm{B}}}{\partial \mathrm{Q}_{\mathrm{B}}}}{\partial \mathrm{P}_{\mathrm{B}}}+\frac{1}{2 \mathrm{t}} \frac{\partial \mathrm{Q}_{\mathrm{B}}}{\partial \mathrm{U}}
$$

Thus an exact value for $\partial \mathrm{P}_{\mathrm{B}} / \partial \mathrm{P}_{\mathrm{A}}$ under Cournot behavior requires values for the slope of $\mathrm{B}$ 's demand and the responsiveness of that demand to changes in the market boundary. In other words, a specific rather than general demand function would have to be assumed. However, since $\partial \mathrm{Q}_{\mathrm{B}} / \partial \mathrm{P}_{\mathrm{B}}<0$ unless demand is perfectly inelastic, and $\partial \mathrm{Q}_{\mathrm{B}} / \partial \mathrm{U}<0$, it is obvious that $1<\partial \mathrm{P}_{\mathrm{B}} / \partial \mathrm{P}_{\mathrm{A}}<0$.

${ }^{7}$ It should be stressed that these arguments apply to expectations about the ultimate equilibrium, not about some sort of sequential adjustment process that could be conceived. Thus, we follow Bresnahan (1981) and the other writers on the CCE concept in emphasizing expectations about equilibria.

8 Note that the Cournot conjecture from footnote 6 is identical to the Loschian conjecture when demand is perfectly inelastic.

9If we drop the duopoly assumption and allow for more oligopolists, the CCE can also change. Perry (1982) demonstrated this in a spaceless setting.

10 It should be noted that Boyer and Moreaux demonstrated that "any sustainable pair of production levels" in a spaceless duoply "can be obtained as a consistent conjectural equilibrium" once conjectures are not restricted to be constant (1983, p. 25). A primary purpose for introduction of the CCE concept was to reduce the range of indeterminancy inherent in the 
oligopoly problem. In fact, Bresnahan wrote that he had "solved, in one sense the oligopoly problem" by deriving the CCE (1981, p. 943). However, Boyer and Moreaux's findings led them to conclude that "the fundamental inderterminacy of the solution will not be eliminated by the recourse to consistency requirements" (1983, p. 39). This is not the case with sophisticated behavior in a spatial setting, however.

\section{REFERENCES}

Beckmann, Martin. "Spatial Cournot Oligopoly." Regional Science Association Papers. 38 (1972). 37-47.

Benson, Bruce L. "Loschian Competition Under Alternative Demand Conditions." American Economic Review. 70 (December 1980). 10981105. "Spatial Microeconomics: Implications for the Use of Concentration Ratios to Represent Market Power." Review of Regional Studies. 9 ( Winter 1979). 1-16. and Robert M. Feinberg. "An Experimental Investigation of Spatial Equilibria Impacts of Information." Southern Economic Journal. 54 (1988). forthcoming.

Boyer, M. and M. Moreaux. "Conjectures, Rationality and Duopoly Theory." International Journal of Industrial Organization. 1 (1983). 23-41.

Bresnahan, Timothy. "Duopoly Models with Consistent Conjectures." American Economic Review. 71 (December 1981). 934-945.

Capozza, Dennis and K. Attaran. "Pricing and Spatial Dispersion of Firms Under Free Entry." Journal of Regional Science. 16 (August 1976). 167-182. and Robert Van Order. "A Generalized Model of Spatial Competition." American Economic Review. 68 (December 1978). 896-908. and "A Simple Model of Spatial

Pricing Under Free Entry." Southern Economic Journal. 44 (October 1977). 361-367. a and "Pricing Under Spatial

Competition and Spatial Monopoly."Econometrica.

45 (September 1977). 1329-1338. b and . "Unique Equilibria, Pure

Profits, and Efficiency in Location Models." American Economic Review. 70 (December 1980). 1046-1053.
Chamberlin, Edward H. The Theory of Monopolistic Competition, 8th Edition. Cambridge, Mass.: Harvard University Press, 1933.

Dorward, Neil. "Impacts of Distance on Microeconomic Theory: A Critique." Manchester School. 49 (September 1981). 145-469.

Ferguson, Charles. Microeconomic Theory. Homewood, Ill.: Irwin, 1969.

Greenhut, M.L., C.S. Hung, G. Norman and C.W. Smithson, "An Anomaly in the Service Industry: The Effect of Entry on Fees." Economic Journal. 95 (March 1985). 169-177.

H. Hwang, and H. Ohta. "Observations on the Shape and Relevance of the Spatial Demand Function." Econometrica. 43 (July 1975). 705713.

, and H. Ohta. "Discriminatory and Nondiscriminatory Spatial Prices and Output Under Varying Market Conditions." Welwirtschaftliches Archiv. 111 (1975). 310-332. a and Theory of Spatial Pricing

and Market Areas. Durham, N.C.: Duke University Press, 1975. b

Holt, Charles. "An Experiemental Test of the Consistent-Conjectures Hypothesis." American Economic Review. 75 (June 1985). 314-325.

Hotelling, Harold. "Stability in Competition." Economic Journal. 39 (March 1929). 41-57.

Kamien, M. and N. Schwartz. "Conjectural Variations." Canadian Journal of Economics. 16 (May 1983). 191-211.

Ohta, Hiroshi. "Spatial Competition, Concentration, and Welfare." Regional Science and Urban Economics. 10 (March 1980). 3-16. "The Price Effects of Spatial Competition." Review of Economic Studies. 48 (April 1981). 317-325.

Perry, Martin K. "Oligopoly and Consistent Conjectural Variations." Bell Journal of Economics. 13 (Spring 1982). 197-205.

Smithies, Arthur. "Optimum Location in Spatial Competition." Journal of Political Economy. 49 (June 1941). 423-439. 